Revista Internacional de Apoyo a la Inclusión, Logopedia, Sociedad y Multiculturalidad. Volumen 5, Número 3, Diciembre 2019, ISSN: 2387-0907. DOI: https://doi.org/10.17561/riai.v5.n3.7

\title{
A percepção dos estudantes sobre a importância do uso das tecnologias digitais de informação e comunicação (TIC) no processo de ensino e aprendizagem.
}

\section{Students' perception of the importance of using digital information and communication technologies (ICT) in the teaching and learning process.}

\author{
Rosana Cléia de Carvalho Chaves \\ Universidade Estadual de Roraima - UERR-(Brasil) \\ osanacleia@gmail.com \\ Ivanise Maria Rizzatti \\ Universidade Estadual de Roraima - UERR-(Brasil) \\ niserizzatti@gmail.com.br \\ Noelson Freitas Nascimento \\ Universidade Estadual de Roraima - UERR-(Brasil) \\ noelsonfreitas@hotmail.com
}

Fecha recepción: 15/09/2019

Páginas 72-81

Fecha aceptación: 25/11/2019

\section{Resumo.}

Este artigo se remete a uma abordagem reflexiva sobre a importância da inserção das tecnologias digitais no contexto educativo, para tanto, objetivou-se analisar a percepção dos estudantes do $3^{\circ}$ Ano do Ensino Médio, sobre a importância da inserção das TIC no processo de ensino e aprendizagem. Dessa forma, a abordagem da pesquisa apresenta-se de forma qualitativa, com método descritivo, explicativo, adotando como procedimento a pesquisa participante e em campo, tendo como parâmetro, elementos iniciais da compreensão e análise, quanto à percepção dos estudantes, na verificação e avaliação da inserção das Tecnologias Digitais de Informação e Comunicação (TIC) nas aulas e suas possibilidades na aprendizagem e na ampliação de conhecimentos. Visando mensurar as informações e buscar 0 aprofundamento da percepção dos estudantes, nesta realidade, aplicamos um questionário a 27 alunos na turma do $3^{\circ}$ Ano do Ensino Médio, evidenciando os aspectos relacionados: a importância destes recursos em sala de aula, utilização das TIC pelos professores nas aulas, conhecimento e domínio das TIC e indicadores quanto ao processo de ensino e aprendizagem. A partir da análise dos questionamentos aplicados, evidenciamos na percepção dos estudantes a importância da inserção desses recursos, como elemento motivador na execução das atividades escolares e facilitador da aprendizagem.

Palavras-chave: TIC; percepção; estudantes; ensino; aprendizagem

\section{Abstract.}

This article refers to a reflective approach about the importance of the insertion of digital technologies in the educational context. Therefore, the objective was to analyze the 
perception of the students of the 3rd year of high school, about the importance of the insertion of TIC in the teaching process. learning. Thus, the research approach is qualitative, with a descriptive and explanatory method, adopting the participant and field research as a procedure, having as a parameter, initial elements of understanding and analysis, regarding the students' perception, in the verification and evaluation of the insertion of Digital Information and Communication Technologies (TIC) in classes and their possibilities for learning and knowledge expansion. In order to measure the information and seek to deepen the students' perception, in this reality, we applied a questionnaire to 27 students in the 3rd Year High School class, highlighting the related aspects: the importance of these resources in the classroom, the use of ICTs by teachers in classes, knowledge and mastery of TIC and indicators regarding the teaching and learning process. From the analysis of the applied questions, we highlight in the students' perception the importance of the insertion of these resources, as a motivating element in the execution of the school activities and facilitator of the learning.

Keywords: TIC; perception; students; teaching and learn

\section{1.-Introdução.}

Sabe-se que as tecnologias é uma ferramenta essencial para o nosso dia a dia, assim como também para desenvolver nosso trabalho em sala de aula. Dessa forma, a temática desta pesquisa apresenta a percepção dos alunos do $3^{\circ}$ Ano do Ensino Médio, sobre papel do professor, frente aos desafios da inserção do uso das Tecnologias Digitais de Informação e Comunicação (TIC) no processo de ensino e aprendizagem.

Ao abordar estas questões busca-se compreender a percepção dos alunos frente aos desafios da inserção das Tecnologias Digitais de Informação e Comunicação (TIC) e a postura do professor diante da inclusão da cultura digital e suas contribuições em sala de aula.

Neste contexto, a pesquisa em questão apresenta como objetivo, analisar a percepção dos alunos do $3^{\circ}$ Ano do Ensino Médio, sobre papel do professor, frente aos desafios da inserção das TIC no processo de ensino e aprendizagem. Partindo desse pressuposto, o problema da pesquisa, envolve: Como a relação entre a mediação docente e a inserção das Tecnologias Digitais de Informação e Comunicação (TIC), podem contribuir com o processo de ensino aprendizagem dos estudantes do $3^{\circ}$ Ano do Ensino médio de uma Escola Estadual em Boa Vista/RR?

Neste sentido, percebe-se que a tecnologia é um recurso presente no nosso cotidiano e que a cada momento está evoluindo, trazendo vários benefícios para a vida e assumindo uma função de grande relevância na vida social e escolar do indivíduo. Desse modo, os recursos tecnológicos deram um grande salto e modificou totalmente a vida dos indivíduos, neste cenário de mudanças, até as crianças desde muito cedo, são inseridas em meio a um contexto que lhes oportunizam vivências e experiências no manejo com as tecnologias.

Dessa forma questiona-se: A escola está acompanhando tais avanços? A escola possui recursos tecnológicos necessários para efetivação das atividades escolares? Os professores estão preparados e motivados para inserir tais recursos no processo de ensino e de aprendizagem? Qual a importância das TIC na sala de aula? Assim, para responder tais questionamentos percebe-se a necessidade de se rediscutir, repensar a escola e sua 
inserção na cultura digital, assim como também, a execução de atividades pedagógicas dentro de uma perspectiva inovadora, desafiadora e significativa, integrando-as ao contexto da aprendizagem ao cotidiano dos alunos.

Diante da percepção dos respectivos alunos, podemos evidenciar os aspectos relacionados à utilização das TIC na realidade local da Escola Estadual em Boa Vista/RR, a importância destes recursos em sala de aula, a inserção e o domínio das TIC pelos os professores, os pontos positivos e negativos na utilização das TIC e indicadores quanto ao processo de ensino e aprendizagem em sala de aula, como ferramenta e auxílio nas aulas, sendo um novo recurso que favorece grandemente o processo de informação e comunicação, estimulando a aprendizagem.

Neste contexto, compreendemos a utilização das Tecnologias Digitais de Informação e Comunicação (TIC) no âmbito escolar, como fonte que auxilia o professor na dinâmica do processo de ensino e aprendizagem, ampliando a interatividade entre aluno e professor, aproximando assim o processo de ensino ao processo de aprendizagem. Em suma, a utilização das TIC, facilita o fortalecimento da coletividade, não somente no ambiente escolar, mas também fora da escola, garantindo uma mudança significativa e desafiadora, integrando-as e aproximando assim o aluno da aprendizagem.

\section{2.-Inclusão digital: perspectiva de integração das tecnologias digitais de informação e comunicação (tdics) na sade aula.}

Como sabemos as crianças e adolescentes desde muito cedo estão e constante contato com as Tecnologias Digitais de Informação e Comunicação (TIC), dessa forma, as crianças nos primeiros anos escolares já utilizam e demonstra uma aproximação junto aos vários recursos tecnógicos, como: celular, computador, tablete, vídeo games entre outros elementos indicadores da à cultura digital.

Neste caso vale ressaltar que, muitas vezes as crianças ainda não domina a escrita e leitura, porém de forma peculiar demonstram interesse no manuseio desses recursos.

Para Moran $(2000$, p. 37$)$ "A criança também é educada pela mídia, principalmente pela televisão. Aprende a informar-se, a conhecer - os outros, o mundo, a si mesma-, a sentir, a fantasiar, a relaxar, vendo, ouvindo, "tocando" as pessoas na tela, pessoas estas que lhe mostram como viver, ser feliz e infeliz, amar e odiar".

Percebe-se então que as crianças e adolescentes desde pequenas têm contato com diversas mídias e através delas elas aprendem muitas coisas. As mídias são um dos meios pelos quais as crianças aprendem de forma prazerosa e dinâmica, seu uso na escola favorece em muito a obtenção de conhecimentos.

Neste foco, compreende-se as Tecnologias Digitais de Informação e Comunicação (TIC) como um conjunto de recursos presente no nosso cotidiano e que a cada momento está evoluindo, trazendo vários benefícios para a vida e assumindo uma função de grande relevância na vida social e escolar do indivíduo.

A este respeito Haetinger (2005, p. 39) declara: "A escola jamais poderia ser indiferente, pois se constitui um lugar de posturas e mudanças sociais. É na escola onde se encontra o âmago das modificações de origem social".

Dessa forma, em se tratando dos avanços das novas tecnologias, na percepção dos alunos do $3^{\circ}$ Ano da Escola Estadual Estadual em Boa Vista-RR, consideram que as TIC como 
ferramenta e auxílio na execução de atividades aulas, sendo um recurso que favorece grandemente o processo de informação e comunicação, estimulando a aprendizagem.

Neste sentido, possibilita o aumentando da autoestima dos alunos, além de permitir aos alunos interação entre os colegas e com os conteúdos estudados. Neste contexto, é importante utilizar os recursos disponíveis e variados como forma de integrar a prática profissional com sua vivência e experiência do aluno.

Assim torna-se indispensável à utilização TIC tendo em vista que, tais recursos auxilia a dinâmica do processo de ensino e aprendizagem, amplia a interatividade entre aluno e professor, levando um mundo de conhecimento para dentro da sala de aula, através de várias formas tem uma colaboração na mudança de paradigmas tradicionais em relação ao processo de ensino e aprendizagem, ou seja, elas se apresentam como uma nova maneira de ensinar e aprender.

As evidências das TIC tem influenciado a aprendizagem dos alunos de forma significativa, pois tais recursos oportunizam o diálogo, fortalece a interação com colegas não somente no ambiente escolar, mas também fora da escola, garantindo uma mudança significativa e desafiadora, integrando-as e aproximando o aluno da aprendizagem.

Em suma, diante do exposto, percebemos que, os usos das Tecnologias Digitais de Informação e Comunicação (TIC) favorecem o aprendizado dos alunos, pois segundo a mensuração quanto a percepção dos alunos, vimos que através da sua utilização, ambos aprendem com muito mais entusiasmo e interagem de forma prática, o aprendizado acontece de forma dinâmica e interativa.

\section{3.-A Importância das tecnologias digitais de informação e comunicação (TIC) no processo de ensino e aprendizagem.}

Amplas são as discussões acerca das questões que envolvem a prática pedagógica no processo de desenvolvimento de ensino e aprendizagem, enquanto seu papel, seu objetivo e sua função social, evidenciando assim as contribuições na formação do indivíduo.

Neste caso, faz-se necessário pontuar a relevância das concepções, influências e a utilização das TIC frente às questões educacionais.

Tais abordagens oportunizam momentos de discussão e reflexão no que se refere à valorização do ensino na construção do conhecimento e a utilização das tecnologias no desenvolvimento do processo de ensino e aprendizagem.

Nesta perspectiva, as Tecnologias Digitais de Informação e Comunicação (TIC), podem ser incorporadas na escola como suporte e auxílio quanto as atividades escolares, dessa forma, as TIC começaram a adentrar no contexto diário de sala de aula, integração às atividades de sala de aula.

Neste sentido, [...] o processo ensino-aprendizagem deve incorporar cada vez mais o uso das tecnologias digitais para que os alunos e os educadores possam manipular e aprender a ler, escrever e expressar-se usando essas novas modalidades e meios de comunicação, procurando atingir o nível de letramento (Valente, 2007, p. 38).

Conforme Valente (2009, p.3): "É importante utilizar das TIC para [...] potencializar as práticas pedagógicas que favoreçam um currículo voltado ao desenvolvimento da autonomia do aluno na busca e geração de informações significativas para compreender o mundo e atuar em sua reconstrução, no desenvolvimento do pensamento crítico e auto-reflexivo do 
aluno, de modo que ele tenha capacidade de julgamento, auto realização e possa atuar na defesa dos ideais de liberdade responsável, emancipação social e democracia".

Tais atividades levaram à compreensão de que o uso das tecnologias de informação e comunicação - TIC na escola, principalmente com o acesso à Internet, contribui para expandir 0 acesso à informação atualizada e, principalmente, para promover a criação de comunidades colaborativas que privilegiam a comunicação, permitem estabelecer novas relações com o saber que ultrapassam os limites dos materiais instrucionais tradicionais e rompem com os muros da escola, articulando-os com outros espaços produtores do conhecimento, o que poderá resultar em mudanças substanciais em seu interior.

De acordo com Haetinger (2005), "a tecnologia evidencia-se em todos os seguimentos sociais, é um elemento importante nas atividades diárias". Neste aspecto, o mesmo autor cita ainda que, "se continuar não interagindo o ensino com a vida prática dos alunos está correndo o risco de ficar falando sozinho, na sala de aula ou no universo virtual". (Haetinger, 2005 p.43).

Segundo as considerações do autor, percebe-se que professores e a escola necessitam evidencia-las em seu contexto, contudo, precisam conhecer, compreender, operacionalizar e fazer uso das tecnologias de forma complementar para assim enriquecer a dinâmica do processo de aprendizagem dos alunos.

Com isso, percebe-se que as TIC ampliam perspectivas de compreensão da prática pedagógica pautada em um novo olhar, isto é, na inserção de posturas e mudanças educacionais diante das contribuições dos recursos tecnológicos no âmbito escolar.

Neste contexto, vale ressaltar que, as evidências pontuadas a partir da percepção dos alunos percebe-se a necessidade de rediscutir e repensar a prática pedagógica dentro de um prisma profissional que perceba a necessidade de planejar e executar estratégias e atividades pedagógicas dentro de uma perspectiva inovadora, desafiadora e significativa integrando-as ao contexto da aprendizagem dos alunos.

Como nos diz Haetinger (2005, p.39), "A escola jamais poderia ser indiferente, pois se constitui um lugar de posturas e mudanças sociais. É na escola onde se encontra o âmago das modificações de origem social". Diante dos avanços tecnológicos consideramos o uso das TIC como ferramenta e auxílio nas aulas, sendo um novo recurso que favorece grandemente o processo de informação e comunicação, estimulando a aprendizagem.

Conforme Barreto (2000, p.134): "o acesso à mídia impressa e eletrônica, ao vídeo, ao computador, às redes e apropriação de suas linguagens e estéticas, não é uma utopia ou um desvario, é a condição básica da habitação do cidadão ao diálogo social, afetivo, político, profissional, o cidadão da sociedade informático-mediática necessita adquirir habilitação técnica e linguística que lhe permita transitar e sobreviver no meio informacional na qual está imerso".

Diante do exposto, percebe-se que as evidências em nosso atual contexto educativo, tem influenciado a aprendizagem dos alunos de forma significativa, pois a dinâmica do processo de ensino e aprendizagem, possibilita a interatividade e ampliam conhecimentos.

Corroborando com esse pensamento Haetinger (2005, p.71) ainda acrescenta que:" em nosso trabalho de educadores devemos sempre oportunizar aos alunos 0 acesso à informação e a construção de conhecimentos coletivos. Ao oferecermos este tipo de vivência, buscamos a motivação do aluno e o comprometimento do mesmo com a aprendizagem individual e do grupo ao qual ele pertence". 
A este respeito, faz-se necessário que o professor juntamente com a escola com busque mecanismos que propiciem o desenvolvimento de estratégias significativas entre 0 aprender e ensinar, pois tal prática facilita o fortalecimento da coletividade, possibilita mudanças significativas e desafiadoras, integrando e aproximando o aluno da aprendizagem.

Neste sentido, Valente, (2007, p.21) afirma que: " adequar o emprego da tecnologia, o professor deverá ser 0 elemento fundamental nesta mudança de mentalidade e atitude, inclusive com uma nova visão a respeito do erro não mais como punição, mas como oportunidade para aprender, desenvolver a autonomia e a flexibilização de um sistema rígido, centralizado e controlador".

Assim, refletir sobre o papel do professor neste processo é compreender a importância de sua mediação entre o ensino e a aprendizagem, possibilitando condições para que 0 aluno exerça sua ação de aprender de forma participativa nas diferentes situações do cotidiano escolar, mediando e facilitando a aprendizagem promovendo situações de aprendizagem, intervindo e contribuindo para a evolução e o sucesso do aluno.

Partindo dessa premissa percebe-se que, o papel do professor é de grande importância, pois assume a função de mediador entre o processo de ensino e aprendizagem, organizando situações de aprendizagem, intervindo e contribuindo para o sucesso do aluno.

Como nos diz Freire (1996, p.34) "O ato de educar não é uma doação de conhecimento do professor ao educando, nem transmissão de ideias mesmo que estas sejam consideradas muito boas. Ao contrario, é uma contribuição no processo de humanização. Processo esse de fundamental importância para o exercício do seu trabalho".

Em suma, o professor possibilitará condições que conduzam o aluno à aprendizagem dentro de uma perspectiva de combinação de atividades propostas, equipando as ações executadas pelos alunos, na tentativa de compreender e assimilar conhecimentos através de mecanismos que viabilize o seu desenvolvimento cognitivo levando a aprender a aprender.

\section{4.-Metodologia.}

A pesquisa foi realizada em uma Escola Estadual em Boa Vista/RR localizada na Zona Oeste. A este respeito, a trajetória metodológica desta pesquisa configurou-se em uma abordagem da pesquisa apresenta-se de forma qualitativa, com método descritivo, explicativo, adotando como procedimento a pesquisa participante e em campo, tendo como parâmetro, elementos iniciais da compreensão e análise, quanto à percepção dos alunos, na verificação e avaliação da inserção das Tecnologias Digitais de Informação e Comunicação (TIC) nas aulas e suas possibilidades na aprendizagem e na ampliação de conhecimentos. Visando mensurar as informações e buscar 0 aprofundamento da percepção dos estudantes, nesta realidade, aplicamos um questionários a 27 alunos na turma do $3^{\circ}$ ano do Ensino Médio, evidenciando os aspectos relacionados: a importância destes recursos em sala de aula, contendo 09 questões, sendo 04 questões abertas, 05 questões fechadas, que teve como propósito traçar o perfil da turma de estudantes, bem como a percepção do frente à utilização dos recursos tecnológicos no contexto de sala de aula e suas contribuições para a aprendizagem. 


\section{5.-Resultados e discussão.}

Considerando o debate sobre a percepção dos alunos sobre papel do professor, frente aos desafios da inserção das TIC no processo de ensino e aprendizagem.

Vimos que, um dos elementos iniciais para análise e interpretação de dados, bem como sua mensuração de informações são decorrentes da aplicação de questionário aos alunos. Sendo assim, a respectiva análise evidencia aspectos pautados na percepção de 27 estudantes, sendo 10 estudantes do sexo feminino e 17 estudantes do sexo masculino de uma turma do $3^{\circ}$ Ano Ensino Médio de uma Escola Estadual de Boa Vista-RR.

De acordo com a análise dos questionamentos quanto ao uso dos recursos tecnológicos usados escola obtivemos os seguintes resultados, como demonstra na Figura 1.

Figura 01 - Os professores utilizam as TIC na sala de aula.

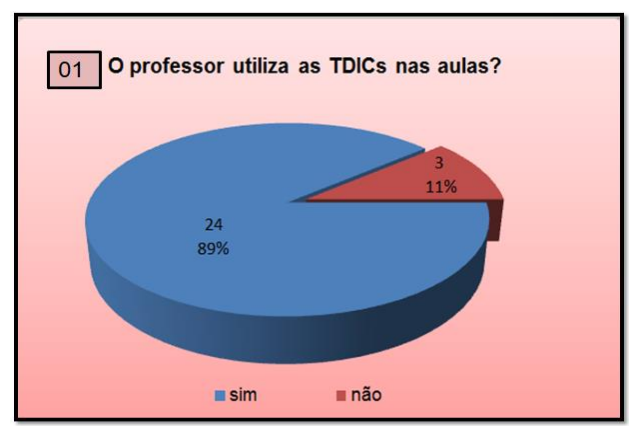

Fonte - própria

Neste contexto, Moran (2013, p.33) afirma que: "a chegada das tecnologias [...] traz novas possibilidades ente aí que reside o desafio do professor. Como utilizar essa tecnologia em sala de aula"? Diante das palavras do autor, percebe-se que cabe ao professor utilizar tais recursos como aliados a aula, a fim de complementar possibilidade de atividades próxima da realidade do aluno.

Neste contexto, a análise a figura 02, pontua questionamentos aos alunos: você considera importante a utilização das TIC na execução das atividades escolares? Mediante resposta ao questionamento, obtivemos $74 \%$ dos alunos afirmaram que sim, 19\% afirmaram não ter importância e 7\% deixaram em branco.

Figura 02. A utilização das TIC na execução das atividades escolares 


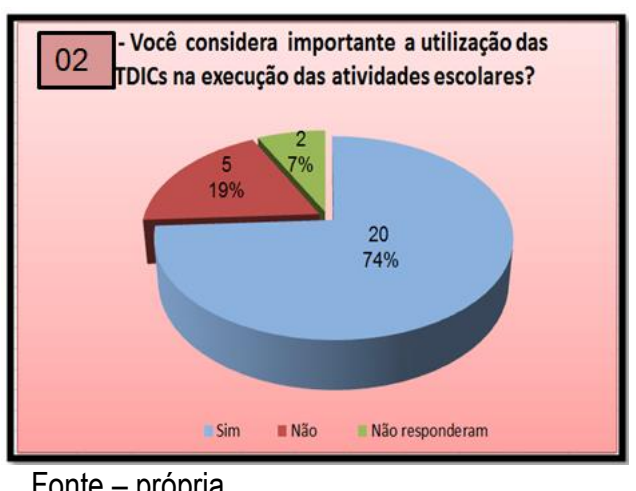

Fonte - própria

Em se tratando das disciplinas que mais utilizam as TIC na sala de aula, obtivemos: Biologia $26 \%$, Portugues $22 \%$ e Física 19\%, uma grande representatividade na escolha das disciplinas.

Figura 03 - Disciplina que os estudante mais gostam e disciplina que menos gostam e apresentam dificuldades.

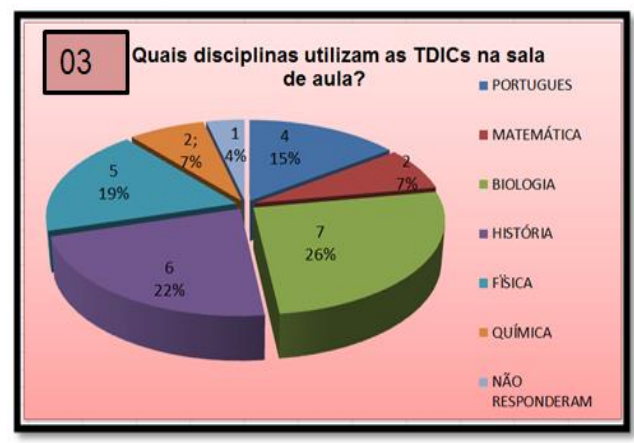

Fonte - própria

Quando questionados sobre os Recursos Tecnológicos mais utilizados nas aulas, 15 alunos, correspondendo a 56\%, apontaram o PC/Notebook, TV e DVD, 9 alunos afirmaram sendo e data show: $33 \%$ e afirmaram 1aluno, equivalente a $7 \%$ afirmaram ser câmera fotográfica digital e $2 \%$,equivalendo a $4 \%$ trata da máquina fotográfica.

Figura 04 - Os Recursos tecnológicos mais utilizados em sala de aula pelos professores na Escola Estadual do $3^{\circ}$ Ano Ensino Médio de uma Escola Estadual de Boa Vista-RR. 


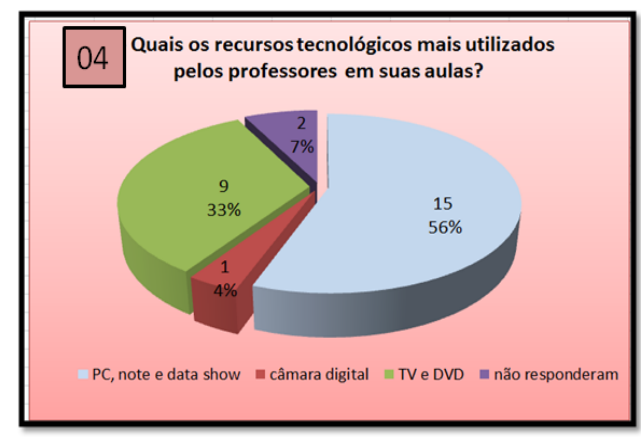

Fonte - própria

Diante da análise dos questionários, vimos que os Recursos Tecnológicos permitem auxiliar e dinamizar o processo de ensino e aprendizagem. A este respeito, para introduzir outras mídias como ferramenta e auxílio nas aulas, os estudantes destacam vantagens e desvantagens na utilização desses recursos no contexto de sala de aula.

Em se tratando da Figura 05 - Quanto a importância dos recursos tecnológicos na facilitação do processo de aprendizagem dos estudantes da Escola Estadual do $3^{\circ}$ Ano Ensino Médio de uma Escola Estadual de Boa Vista-RR, obtivemos os respectivos dados:

Figura 05. A importância dos recursos tecnológicos na facilita doção processo de aprendizagem.

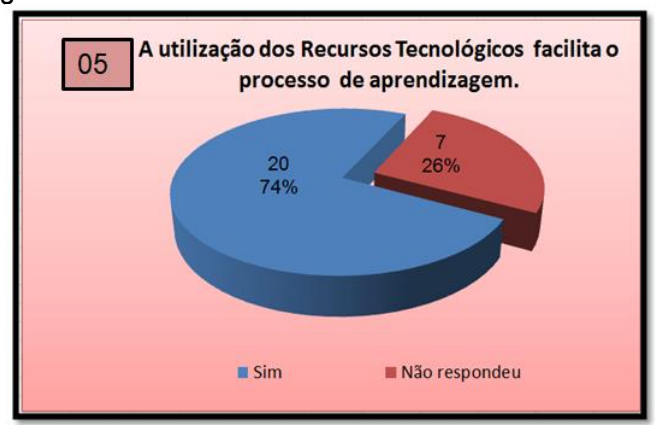

$$
\text { Fonte - própria }
$$

Mediante a análise da Figura 05 - que enfatiza a percepção dos estudantes quanto a utilização do Recursos Tecnológicos em sala de aula, ambos foram categóricos em afirmar que $74 \%$ acreditam na utilização desses recursos no contexto escolar, Neste caso, vale destacar que tivemos um expressivo número de estudantes, a saber $26 \%$, julgam que os recursos tecnológicos não contribuem com o processo de aprendizagem dos estudantes.

\section{6.-Considerações finais.}

A partir da análise dos questionários quanto à percepção dos estudantes de uma turma $3^{\circ}$ Ano Ensino Médio da Escola Estadual de Boa Vista-RR, sobre questões que envolvem a 
verificação, a inserção da utilização das tecnologias durante as aulas e suas possibilidades de ampliação de conhecimentos, percebeu-se que, os estudantes avaliaram como positivas a prática das novas tecnologias na educação, enfatizando as contribuições na aprendizagem, por deixar a aula mais animada, divertida e por possibilitar mais interação com os colegas diante dos conteúdos trabalhados durantes as aulas.

Partindo desse pressuposto, entendemos que, a utilização das TIC, merece ter seu lugar de destaque no processo prático da sala de aula, por aguçar e estimular cada vez mais a capacidade de inquirir, pesquisar e descobrir de maneira que os alunos aprendam e prove de outras experiências.

Em linhas gerais vimos na percepção dos alunos, que o professor é o mediador desse processo, portanto tem um papel significativo, tendo em vista que, é dele a missão de buscar alternativas em verificar, acompanhar e sanar as possíveis dificuldades de aprendizagem dos estudantes.

Dessa forma, ao abordar estas questões percebeu-se que os professores precisam conhecer, compreender, operacionalizar e fazer uso das tecnologias no seu cotidiano, para dessa forma complementar e enriquecer a dinâmica do processo de aprendizagem dos alunos.

Diante do exposto, as evidências pontuadas pelos alunos in loco, demonstram a necessidade de se rediscutir, repensar na execução de atividades pedagógicas dentro de uma perspectiva inovadora, desafiadora e significativa, integrando-as ao contexto da aprendizagem, contudo, a presença dos recursos tecnológicos no cotidiano escolar enriquecem as estratégias de ensino e possibilita a dinamização da aprendizagem dos conteúdos, favorecendo o processo de informação e comunicação, possibilitando a elevação da autoestima dos alunos, além de permitir adaptação de conteúdos, visando um melhor rendimento escolar.

Em suma, as discussões de enfoque desta pesquisa possui grande relevância para a comunidade da escola campo, por proporcionar reflexão e fomentar a prática pedagógica a partir da mediação docente tendo como suporte às ferramentas tecnológicas no âmbito escolar.

\section{7.-Referências.}

Barreto, A.A. (2000). Os Agregados de informação: Memórias, esquecimento e estoques de informação. $4^{\text {a} e d . ~ S a ̃ o ~ P a u l o: ~ S c i p i o n e . ~}$

Freire, P. (1996). Pedagogia da Autonomia: saberes necessários à prática educativa. São Paulo: Paz e Terra.

Haetinger, M.G. (2005). O Universo Criativo da Criança na educação. Disponível em: www.maxcriar.com.br/. Acesso em: 19/09/2019.

Moran, J. (2000). Ensino e aprendizagem inovadores com tecnologias audiovisuais e telemáticas, in: Moran, J., Masetto, M. e Behrens, M. (2000). Novas tecnologias e mediação pedagógica. Campinas: Papirus.

Valente, J. (2007). O uso inteligente do computador na educação. Porto Alegre: Pátio. 